\title{
Socially based discrimination against clinically appropriate care
}

A longer version of this article was published at cmaj.ca

$\mathrm{T}$ he Human Rights Challenge filed Aug. 18 in Ontario by Amir Attaran with Anna Ilha brought national attention to discrimination against socially disadvantaged Canadian women/couples who are seeking clinically appropriate care.

Ontario publicly funded in vitro fertilization (IVF) from 1985 to April Fool's Day 1994, ' when it was "delisted" except for completely blocked fallopian tubes. This delisting, foolish from a scientific, clinical, social, ethical and even economic perspective, ${ }^{1-4}$ excluded most Canadians with clinically appropriate indications for IVF from having children, including those with oocyte depletion (common in cancer survivors and women over 35), scarred fallopian tubes, endometriosis and inadequate sperm. These Canadians were also generally excluded from being chosen by an adopting-out birth mother (many of whom may want a white picket fence) ${ }^{3}$ and from international adoption (expensive). With Ontario delisting IVF, other provinces did not go forward with funding IVF.

Ten years after Ontario delisted IVF, Canada's Act Respecting Assisted Human Reproduction and Related Research became law. Although this act is similar to legislation in Australia, Western Europe and other countries in promoting the safety of women undergoing assisted reproduction and health of children born thereof, Canada is alone in not funding IVF. ${ }^{3}$ Indeed, only $15 \%$ of Canadian women with clinical indications access IVF compared with countries that fund IVF. ${ }^{5}$ This Canadian policy may be discriminatory in light of Section 2(E) of our Act which states, "persons who seek to undergo assisted human reproduction procedures must not be discriminated against ... including on the basis of sexual orientation or marital status." ${ }^{\prime 3}$ The act's use of the word "including" suggests other social factors are also not appropriate bases for discrimination.
Ontario's 1994 delisting of IVF was based on misinterpretation of the Royal Commission on Reproductive Technologies' 1993 recommendation to "proceed with care," as well as a lack of understanding of the financial repercussions of refusing to fund IVF and insensitivity to the experience of the many Canadians who want to be a parent. The lack of understanding that allowed Ontario to "proceed" only for its wealthier citizens, and not to "care" for its socially less advan-

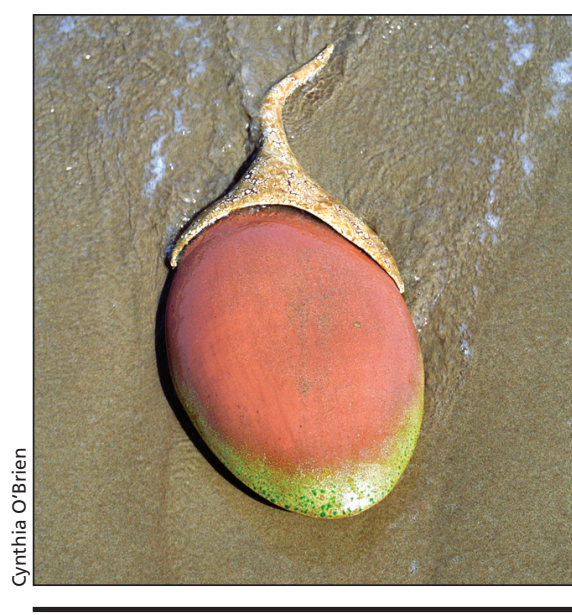

Cynthia O'Brien's clay sculpture, "Emergence One" (2009), represents a sperm.

taged citizens continues as reflected in comments posted on the Globe and Mail's online discussion board the day following its coverage of the Attaran human rights challenge, including: blaming women "over the age of 28 " for delaying having children (when social factors may force women and men to delay), and worrying that we would have to "pay a lot more in taxes" (when, in fact, public funding of IVF would benefit provincial coffers ${ }^{1,3,4}$ ).

IVF, especially with single embryo transfer, prevents the high-order multiple pregnancies that result when women, financially excluded from accessing IVF, "choose" gonadotrophin fertility drugs. These high-order multiple pregnancies are associated with extreme premature birth and huge costs of neonatal intensive care and long-term support of surviving children with cerebral palsy, blindness, and cognitive and other impairments. ${ }^{1,3,4}$ These costs were recognized in Quebec's recent decision to publicly fund IVF, and in the Aug. 26, 2009 release of the Ontario Expert Panel on Infertility and Adoption Report.

According to clinician and researcher Ed Hughes, the reasons why IVF has remained unfunded for so long in Canada, are that "sub-fertile Canadians are largely invisible" and "poorly understood," and the medical profession has not lobbied for IVF funding, as noted in the Nova Scotia Supreme Court decision against public funding of IVF. ${ }^{4}$

The success of Terry Buffett's 2006 human rights challenge, resulting in the Canadian Armed Forces paying for his wife's IVF cycles and amending its policy regarding IVF funding, suggests clinically appropriate care may indeed be a human right in Canada. If the Attaran human rights challenge is successful, all provinces may not only be forced to end their discrimination against socially disadvantaged Canadians who want clinically appropriate infertility treatment, but also to stop the creeping discrimination of two-tiered medicine, including access to more expensive, but more effective new clinical strategies.

\section{Jeff Nisker MD PhD}

Professor of Obstetrics and

Gynaecology and Oncology

Schulich School of Medicine and

Dentistry

The University of Western Ontario London, Ont.

\section{REFERENCES}

1. Nisker JA. Anniversary of injustice: April fool's day, 1994. Will the enactment of Bill C-6 be the birthday of equitable reproductive health care in Canada. $J$ Obstet Gynaecol Can 2004;26:321-4

2. Hughes EG, Beecroft ML, Wilkie V, et al. A multicentre randomized controlled trial of expectant management versus IVF in women with Fallopian tube patency. Hum Reprod 2004;19:1105-9.

3. Nisker J. Distributive justice and infertility treatment in Canada. J Obstet Gynaecol Can 2008:30:425-31.

4. Hughes E. Access to effective fertility care in Canada. J Obstet Gynaecol Can 2008;30:389-93.

5. Collins J. An international survey of the health economics of IVF and ICSI. Hum Reprod Update 2002;8:265-77.

All editorial matter in CMAJ represents the opinions of the authors and not necessarily those of the Canadian Medical Association. 